How to cite this paper:

Abdus-Samad Temitope Olanrewaju \& Rahayu Ahmad (2018). Examining the information dissemination process on social media during the malaysia 2014 floods using Social Network Analysis (SNA). Journal of Information and Communication Technology (JICT), 17 (1), 141-166.

\title{
EXAMINING THE INFORMATION DISSEMINATION PROCESS ON SOCIAL MEDIA DURING THE MALAYSIA 2014 FLOODS USING SOCIAL NETWORK ANALYSIS (SNA)
}

\author{
Abdus-Samad Temitope Olanrewaju \& Rahayu Ahmad \\ School of Computing, Universiti Utara Malaysia, Malaysia \\ samad.olanrewaju@gmail.com; rahayu@uum.edu.my
}

\begin{abstract}
This article is based on a study which examined the information dissemination process on the social media during the Malaysia 2014 floods by employing the Social Network Analysis. Specifically, the study analyzed the type of network structure formed and its density, the influential people involved, and the kind of information shared during the flood. The data was collected from a non-governmental organization fan page (NGOFP) and a significant civilian fan page (ICFP) on Facebook using NodeXL. The two datasets contained 296 posts which generated different network structures based on the state of the flood, information available, and the needs of the information. Through content analysis, five common themes emerged from the information exchanges for both fan pages which helped in providing material and psychological support to the flood victims. However, only 5\% of the networks' population served as information providers, and this prompted the need for more active participation especially from organizations with certified information. Based on the findings presented and elaborated, this article concluded by stating the implications and recommendations of the study conducted
\end{abstract}

Keywords: social network analysis, disaster, flood, Malaysia, information dissemination, influencers. 


\title{
EXAMINING THE INFORMATION DISSEMINATION PROCESS \\ ON SOCIAL MEDIA DURING THE MALAYSIA 2014 FLOODS \\ USING SOCIAL NETWORK ANALYSIS (SNA)
}

\author{
Abdus-Samad Temitope Olanrewaju \& Rahayu Ahmad \\ School of Computing, Universiti Utara Malaysia, Malaysia
}

samad.olanrewaju@gmail.com;rahayu@uum.edu.my

\begin{abstract}
This article is based on a study which examined the information dissemination process on the social media during the Malaysia 2014 floods by employing the Social Network Analysis. Specifically, the study analyzed the type of network structure formed and its density, the influential people involved, and the kind of information shared during the flood. The data was collected from a non-governmental organization fan page (NGOFP) and a significant civilian fan page (ICFP) on Facebook using NodeXL. The two datasets contained 296 posts which generated different network structures based on the state of the flood, information available, and the needs of the information. Through content analysis, five common themes emerged from the information exchanges for both fan pages which helped in providing material and psychological support to the flood victims. However, only $5 \%$ of the networks' population served as information providers, and this prompted the need for more active participation especially from organizations with certified information. Based on the findings presented and elaborated, this article concluded by stating the implications and recommendations of the study conducted
\end{abstract}

Keywords: social network analysis, disaster, flood, Malaysia, information dissemination, influencers. 


\section{INTRODUCTION}

The rate of disasters which occurred in recent years can be considered high, and it did not leave Malaysia untouched. These disasters inevitably led to both social and environmental damages (Alidmat, Khader, \& Hassan, 2016; Nasaruddin, Ardiansyah, \& Khairul, 2016). A disaster is a natural or manmade occurrence which causes human casualties and loss of properties and the natural environment (Chen, Li, Huang, \& Shih, 2011) which can be natural, technological or health-related and affects many globally. The recent Malaysia floods started on $15^{\text {th }}$ December 2014 and lasted until $3^{\text {rd }}$ January 2015 with twelve states affected and a total of twenty-one human lives lost (Wikipedia, 2015). It is believed to be one of the gravest disasters to have struck the country in decades (Reuters, 2014).

Disasters have complex social impacts because they affect the normal and social order of the people around the affected area. The burden and stress placed on the victims often lead to both physical and psychological distress (Yandong, 2010), prompting the need for quick responses to disasters and effective information dissemination. However, due to the dynamic landscape of a disaster, the flow of information amongst stakeholders can be problematic (Preece, Shaw, \& Hayashi, 2014), which in turn impedes the rescue and volunteer efforts (Thakur, 2012).

The social media is increasingly used for disaster response because it allows for information exchange via conversation and interaction (Yates \& Paquette, 2011). A major strength of the social media is that it provides easy access to communication channels and aids collaboration even when the victims are dispersed (Palen, Hiltz, \& Liu, 2007). Information dissemination on the social media can be helpful to immediately identify people who are spread in various locations during evacuations. Besides, it is equally useful for coordinating volunteering activities and sharing rebuilding information (Belblidia, 2010). Nevertheless, the sharing of information on social media suffers from several challenges. Firstly, according to Uddin \& Amin (2012) the originality and authenticity of information shared on the social media cannot be established. As a consequence, there is a significant rate of misinformation that can occur amongst the citizens involved (Palen et al., 2007). It is dangerous to the victims of the floods and the general population. Secondly, previous studies have shown that during a disaster or crisis, information dissemination and gathering have many loopholes (Lu et al., 2007). It is crucial to identify the key players or information providers on the social media and also the type of information dispersion that transpire during a disaster. In light of these challenges, it was important for this study to examine further the issues highlighted by examining the following research questions: 
1. Who were the key information brokers during the recent Malaysia flood?

2. What type of information exchanges occurred during the recent flood?

3. Did the social network structure change during the flood?

These questions would help to accomplish the sub-objectives of this study. The first question would aid the identification of the key players who actively disseminated information during the flood. The second question would shed light on the groups that these participants belonged to along with the type of information exchanged on the social media during the flood. The last question would provide information that could assist in the construction of the social media structure of the social network; it could also provide understanding of its fluidity during the occurrence of the flood. This study's findings were valuable as a reference for designing an effective information dissemination model on the social media during a disaster. The following section critically reviews related literature to identify the emerging issues pertaining to the study.

\section{LITERATURE REVIEW}

To gain in-depth knowledge on information dissemination through the social media during a disaster, three sub-sections that provide an understanding of the issue need to be examined. The first subsection explains about the dissemination of information during a disaster. The second subsection is an elucidation of the role of the social media when a disaster strikes. The third subsection clarifies the social network analysis (SNA) technique which is significant in this study in order for the social network structure in the social media to be constructed.

\section{Information Dissemination during a Disaster}

Information dissemination is a crucial part of managing a disaster (Matar, Matar, Balachandran, \& Hunaiti, 2016; Sutton, Palen, \& Shklovski, 2008; Vieweg, Hughes, Starbird, \& Palen, 2010). It entails the spread of information from the scene of the disaster (Cote \& Hearn, 2016; Hjorth \& Kim, 2011; Nagar, Seth, \& Joshi, 2012). Additionally, it also involves other related details about the disaster (Chong, Leong, Pan, Bahri, \& Fauzi, 2014; Yates \& Paquette, 2011) and the affected victims (Potter, 2016; Tengku, Wok, Manaf, \& Ismail, 2015; Yandong, 2010). There is a significant growth in research about information dissemination during disasters, over the past few years (L. Hjorth \& Kim, 2011; Hughes \& Palen, 2012; Hughes, St. Denis, Palen, \& Anderson, 2014). 
This is due to the vital role that information dissemination plays with regards to the safety of lives and properties as well as relief coordination (Hjorth \& Kim, 2011; Matar et al., 2016; Thakur, 2012).

It is evident that information dissemination during a disaster by using the social media has shown a significant increase (Matar et al., 2016; Mendoza, Poblete, \& Castillo, 2010). Emergency workers are now making use of the social media for information dissemination purposes (Carley, Malik, Landwehr, Pfeffer, \& Kowalchuck, 2016; St. Denis, Hughes, \& Palen, 2012). Nevertheless, these emergency workers are not well equipped to respond to the information acquired from the public (Hughes, 2014; Potter, 2016).

The increase of information dissemination on the social media can be viewed as a vital addition and alternative to the traditional media as a medium for information exchange during an emergency (Chong et al., 2014; Matar et al., 2016; Tengku et al., 2015). It provides opportunities for collaboration and knowledge sharing (Belblidia, 2010; Nur, Wan, Nor, Zakaria, \& Nazir, 2015). Admittedly, during disasters, information gathering, and the dissemination process are tedious and error prone ( $\mathrm{Lu}$ et al., 2007). The accuracy of information on the social media depends on the spatiotemporal context (Starbird, Palen, Hughes, \& Vieweg, 2010) which makes information on the media difficult to verify and authenticate (Hughes \& Palen, 2012; Matar et al., 2016; Uddin \& Amin, 2012). The difficulty in verifying the information is due to the demanding conditions which make it scattered and heterogeneous (Starbird et al., 2010). The subsequent section extensively discusses the role of the social media during a disaster.

\section{Social Media's Role during Disaster}

Social media is defined as an avenue where users can share data such as information in the form of audio, video, picture or text (Tang, Hämäläinen, Virolainen, \& Makkonen, 2011). The users connect to each other, thereby forming an opportunity for the transmission of information. Connections can be established using a tweet, friends, like, comments and tag, which later form a collection of connections (Pew Research Center, 2013). Kaplan \& Haenlein (2010) in their study classified social media into six broad groups: collaborative projects, blogs and microblogs, content communities, Social Networking Sites (SNS), virtual game worlds and virtual second worlds.

As a channel for collaboration and data sharing, the social media plays a crucial role in related social research (Lai \& Turban, 2008). It serves as data for text mining, sentiment analysis and information retrieval due to 
its ability to generate a significant amount of unstructured data (Matuszka, Vinceller, \& Laki, 2013; Song, Kim, \& Jeong, 2014). The data originates from users' activities as they are mostly online to share real-time data which include happening events or trending topics (Matuszka et al., 2013). Due to the increase in the usage of social media, traditional media have been used less in recent times (Himelboim, Mccreery, \& Smith, 2013) which has a lesser impact during a disaster compared to the social media (Matar et al., 2016; Tengku et al., 2015)

Previous research proved that social media is important for information dissemination among Malaysians (Samsudin, Puteh, Hamdan, \& Nazri, 2013) and the general public to give room for better integration with official disaster response (Sutton et al., 2008). Information dissemination on the social media is helpful in various ways. It helps in risk-reduction during and after the disaster by facilitating information flow (Cote \& Hearn, 2016; Matar et al., 2016), and providing different types of support which help in maintaining the victims' mental health (Yandong, 2010). Using the social media enhances the vital need for information generation and adequate dissemination by members of the public during a disaster (Palen et al., 2007). It is because it offers a more direct channel for information dissemination to the public (Denef, Augustin, Bayerl, \& Kaptein, 2013). This was proven during the Japan tsunami, Bosnia floods, and Queensland floods (Bunce, Partridge, \& Davis, 2011; Hjorth \& Kim, 2011; Matar et al., 2016) where it helped in spreading information, and informing families about their safety (Thakur, 2012).

As for its role in disaster support, Hjorth \& Kim (2011) stated that the social media was used as a platform for information dissemination during the 2011 Japan tsunami because it supported different modes of communication where it enabled users to have live updates and relayed information. Nagar et al. (2012) analyzed the 2010 Philippines hurricane, the 2011 Brazilian floods, and the 2011 Japan earthquake with regard to how the news was spread on the social media using twitter data where they formed an isolated network in the Twitter network. Bunce et al. (2011) further elaborated that people experienced the social media in different ways during different phases of the 2011 Queensland floods, namely information monitoring, collaboration activities, and monitoring through information browsing for seeking and consumption.

In the context of Malaysia, the social media was employed for disaster relief and information updates during the 2013 Kuantan Malaysia floods (Chong et al., 2014). In the 2014 Malaysia floods, it was used for knowledge sharing (Nur et al., 2015). Tengku et al. (2015) exploited the U\&G theory where 
it was found that users during the disaster period were unwilling to share information from popular figures. Instead, information from people whom they shared physical contacts with or civilians who were on the sites of the flood was preferred. Such similarity was also found during the 2013 Boston Marathon bombings incident where the public was focused on the heroic acts of the civilians rather than the professionals (Cote \& Hearn, 2016). In the Bosnia 2015 floods, the social media was used to mitigate the threats of the flood and increased the spread of information (Matar et al., 2016).

In analyzing the network structure formed, Smith (2014) pointed out that social networking sites have six different types of patterns based on the way the users interact on the social platform. They are polarized, tight crowd, brand, community, broadcast, and support, with each of them having its distinct property. These properties are in respect of their information- spreading ability and how their relationships are formed. Information is derived from the generated network structure using the social network analysis (SNA), which is elaborated in the upcoming section.

\section{Social Network Analysis in Social Media}

SNA is a technique for modeling communication patterns in a social network and it highlights important people in the network (Akhtar, Javed, \& Sengar, 2013). It visually studies and examines the connections that exist between actors (people, societies, communities) and other entities (Kelly \& Autry, 2011). Such visualization allows the representation and measurement of degrees and patterns of relationships among the entities (Scholand, Tausczik, $\&$ Pennebaker, 2010). The dynamics of the network and identification of the main network changes are identified using different metrics. They include degree centrality which is calculated by the number of unique edges that are linked to the vertex. It has both in-degree and out-degree. In-degree means the number of edges that are directed to the vertex while the outdegree is the number of edges that go out of the vertex. The sum of both the in-and out-degrees is referred to as the social tie strength (Hansen, Shneiderman, $\&$ Smith, 2011). The betweenness centrality denotes the number of people that get connected through the individual direct connections. The closeness centrality is determined by how a person is close to others in the network which is a degree of the average shortest distance from each vertex to each other's vertex. The eigenvector centrality is a measurement that takes both the extent of the vertex and the vertices that are connected to each other. It helps in revealing the key links in information dissemination (Hansen et al., 2011). That said, the ensuing section explains the core of the study which is the methodology. 


\section{METHODOLOGY}

As the main technique, SNA was utilized to identify the type of network structure formed and the main information brokers/influencers. Four stages were involved which included data collection, data pre-processing, network clustering and analysis, and content analysis.

\section{Data Collection}

In the first stage, data were collected from two sources which were the nongovernmental organization fan page (NGOFP) and a significant civilian fan page (ICFP) on Facebook using NodeXL to examine the information dissemination process on the social media. These two data sources were selected because previous research had highlighted the roles of civilians and organizations during disasters (Denef et al., 2013; Hjorth \& Kim, 2011; Matar et al., 2016; St. Denis et al., 2012) and the tendency of the public to trust them more than the official sources (Tengku et al., 2015).

NodeXL is a Microsoft Excel add-in that is used in extracting social media network data and enables the user to perform different kinds of analysis that are based on the media using such data, e.g. Twitter, Email, Facebook and Wikis. It helps in simplifying network analysis by collecting the data, storing and analyzing them to produce a visual network structure (Smith, 2013). This is because it utilizes a highly structured template in storing and retrieving relevant information to generate a graph and its properties on multiple sheets (Hansen et al., 2013). The first data set (NGOFP) was collated from $18^{\text {th }}$ December 2014 to $24^{\text {th }}$ January 2015 and was clustered into during-and postflood groups. The during-flood period extended over 18 days with 97 posts in entirety while the post-flood group covered a period of over 20 days with a total of 42 posts. The whole data set consisted of 139 posts. The data of the ICFP was collated daily from $24^{\text {th }}$ December to $4^{\text {th }}$ January due to its size, and the purpose was to identify changes in the network structure. In the course of this period, 157 posts were collected. Data from $18^{\text {th }}$ till $23^{\text {rd }}$ December 2014 were not represented in the analysis as no information about the flood was identified in the network until $22^{\text {nd }}$ December 2014, and was mentioned only once. Information regarding the flood was consistent on the network from $24^{\text {th }}$ December 2014.

\section{Data Processing}

In the subsequent stage, the collated data was pre-processed by filtering duplicate vertices and tweets followed by the merging of repeated edges. It 
helped in the reduction of data while refining the accuracy of the analysis and preserving the originality of the data (Hansen et al., 2011).

\section{Network and Cluster Analysis}

In the network analysis and clustering stage, the graphs generated were directional. The graphs were analyzed using betweenness centrality, in-degree, out-degree and clustering coefficient to ascertain the influential people in the network, the information disseminators, bridge spanners, and outliers (Hansen et al., 2011). The clustered network based on the Wakita-Tsurumi algorithm was used to identify active posts and cliques within the network (Wakita \& Tsurumi, 2007).

\section{Content Analysis}

At this point, the posts and tweets on the fan pages were analyzed based on their content to identify themes distribution in the posts. It was done using the KH Coder (Higuchi, 2001) which had been employed by Anzai \& Matsuzawa (2013) in analyzing mission statements of Japanese universities. The next section provides the findings of the study and detailed discussion of the results on them.

\section{RESULTS AND DISCUSSION}

The results obtained from both the fan pages were analyzed under six basic categories. The categories were the network structure, posts and cluster analysis, posts content analysis, influencers, graph density and gender activity.

\section{Network Structure}

Table 1

Summary of Comparison between the Two Fan Pages

\begin{tabular}{ccc}
\hline ICFP & NGOFP \\
\hline Network structure & Broadcast pattern $\left(24^{\text {th }}\right.$ and $25^{\text {th }}$ & Community cluster \\
December $)$ & \\
Tight crowd pattern $\left(26^{\text {th }}, 27^{\text {th }}\right.$ and & \\
$28^{\text {th }}$ December $)$ & \\
& Community cluster pattern $\left(29^{\text {th }}\right.$ & \\
December 2014 $-4^{\text {th }}$ January 2015$)$ & \\
\hline
\end{tabular}

(continued) 


\begin{tabular}{lcc}
\hline & ICFP & NGOFP \\
\hline Graph density & 0.126631969 & 0.004 \\
Average participant & 967 & 545 \\
$\begin{array}{l}\text { Information } \\
\text { disseminators and } \\
\text { brokers }\end{array}$ & $5 \%$ & $5 \%$ \\
$\begin{array}{l}\text { Active users } \\
\text { Posts and cluster } \\
\text { analysis }\end{array}$ & $98.2 \%$ & $45 \%$ \\
Gender activity & 157 posts & 120 posts \\
& $31.4 \%$ males and $66.7 \%$ females & $22 \%$ males and $25.1 \%$ \\
& & females \\
\hline
\end{tabular}

Table 1 provides a summary of the network structure and the properties of each dataset during the period of the study. The network structure formed was categorized using the social media patterns highlighted by Smith (2014). The two datasets generated different network structures. In Table 1, the ICFP produces three distinct network structures that are engendered in succession during the flood period. The NGOFP has only a single network structure which is the community cluster structure that is formed because different topics attract a distinct audience, influencers and information source in its distinct cluster (G) (Smith, 2014).

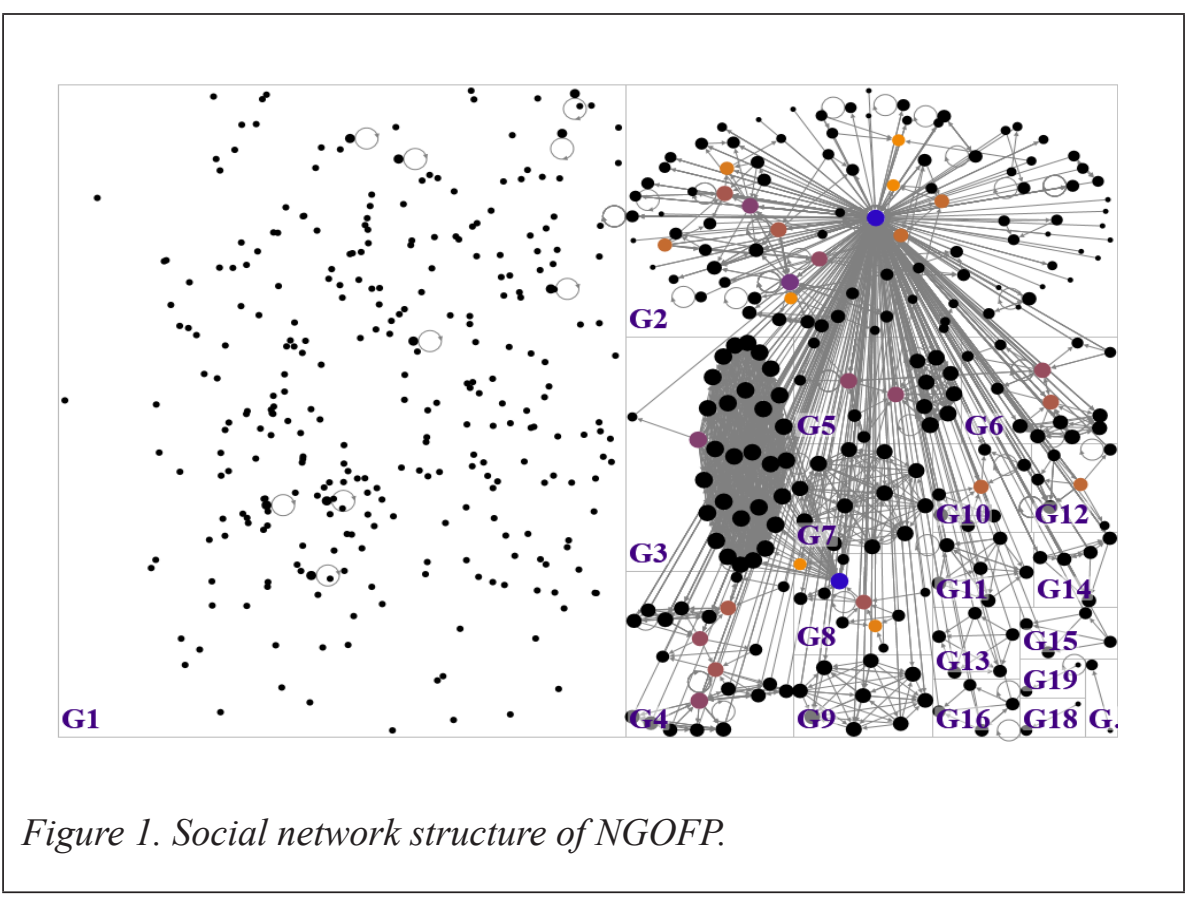




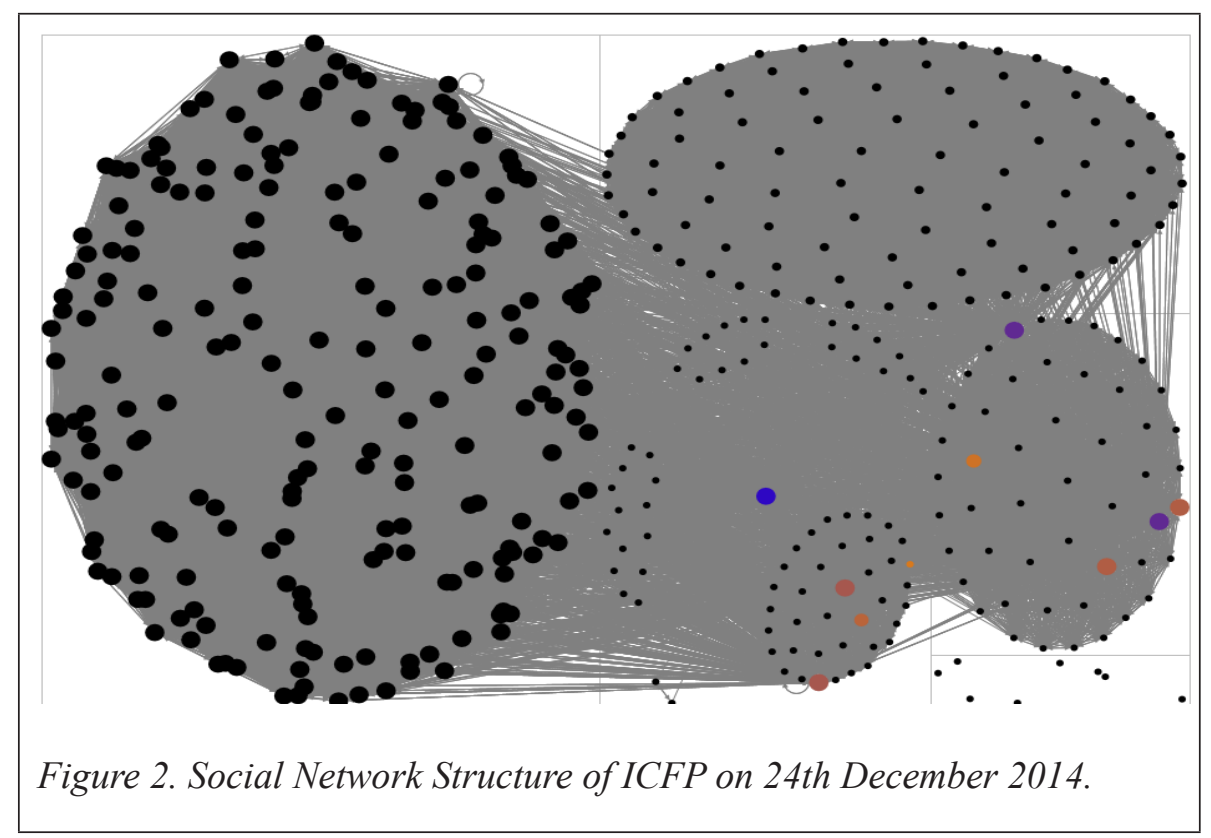

The network structure analysis coupled with the content analysis shows the rate and type of supports these pages offer during the flood phases. The NGOFP clusters cover the whole flood period, i.e. the during-flood phase covering the first to the third week and the post-flood phase covering the fourth to the sixth week, while the ICFP covers the during-flood phase period only. This is due to the large dataset generated. There are changes in the network because of the state of the floods, the information available, and the need for the information. The NGOFP network structure was generated at once due to the low activity carried out on the page; the changes that existed were very subtle and could only be identified through the weekly information evolution that witnessed an evident change similar to that of the ICFP.

The broadcast network pattern was formed at the earliest stage of the flood. This period spanned two days $\left(24^{\text {th }}\right.$ and $25^{\text {th }}$ December). This pattern was formed as a result of the initial stage of the flood during which the flood was recurring and only sketchy information was available. Hence, any crucial information or updates needed to be broadcast, resulting in the broadcast network pattern. At the mid-stage of the flood $\left(26^{\text {th }}, 27^{\text {th }}\right.$ and $28^{\text {th }}$ December $)$, the tight crowd pattern was formed. This pattern emerged since the flood had begun to decline and more information was available to the public. Having more awareness and information about the flood gave room for effective and focused discussions among the public and helped to form the tight crowd pattern. People were more concerned about the importance of helping the affected victims of the 
flood, thus sharing similar aims, and this made the people become highly interconnected with very few outliers.

At the end of the flood period (29th, 30th, 31st December and the 1st, 2nd, 4th January), the community cluster pattern was formed. It was because the flood had almost entirely diminished at this point, and there was considerable information about the flood and the circumstances that surrounded the flood. It enabled people of like minds to discuss in small groups with each of them having their information source and influencers apart from relying on a single source in the early period.

Table 2

Mean Table Displaying the Metrics of Evaluation

\begin{tabular}{lllllll}
\hline Period & $\begin{array}{l}\text { Graph } \\
\text { density }\end{array}$ & $\begin{array}{l}\text { Total } \\
\text { participants }\end{array}$ & $\begin{array}{l}\text { Information } \\
\text { disseminator }\end{array}$ & $\begin{array}{l}\text { Number } \\
\text { of } \\
\text { clusters }\end{array}$ & $\begin{array}{l}\text { Number } \\
\text { of posts }\end{array}$ & Modularity \\
\hline Early & 0.218 & 1168.5 & 4.9 & 87 & 15.5 & 0.438516 \\
Middle & 0.156233 & 547.3333 & 3.513333 & 5.67 & 9 & 0.420608 \\
Late & 0.081367 & 1109.333 & 7.2 & 10 & 16.5 & 0.52754 \\
\hline
\end{tabular}

Table 3

Standard Deviation Table Displaying the Metrics of Evaluation

\begin{tabular}{llccccc}
\hline Period & $\begin{array}{l}\text { Graph } \\
\text { density }\end{array}$ & $\begin{array}{l}\text { Total } \\
\text { participants }\end{array}$ & $\begin{array}{l}\text { Information } \\
\text { disseminator }\end{array}$ & $\begin{array}{l}\text { Number of } \\
\text { clusters }\end{array}$ & $\begin{array}{l}\text { Number of } \\
\text { posts }\end{array}$ & Modularity \\
\hline Early & 0.233062 & 1033.083 & 3.676955 & 115.97 & 7.778175 & 0.193969 \\
Middle & 0.054647 & 390.6332 & 1.030793 & 1.53 & 5.567764 & 0.089503 \\
Late & 0.021536 & 397.1492 & 1.201666 & 2.53 & 4.086563 & 0.099928 \\
\hline
\end{tabular}

According to Tables 2 and 3, it could be seen that over time (the middle and the late period) the network structure stabilized and evolved based on the amount of information available, the graph density, the participation, and the information disseminators. Due to the availability of information, the mean number of posts rose from 9 to 16.5 ; this led to a change in the network structure because there were more deliberations and aggregation which resulted in an increase in clusters, lower graph density and higher graph modularity. The early flood period was an exception because on $25^{\text {th }}$ December there was a sharp rise in the flood activities in Kelantan, Malaysia. It led to a massive 21 posts with 1899 participants which were the highest during the whole flood 
period. It resulted in the emergence of significant clusters, a larger number of posts and surprisingly, a high modularity. It was because, on that day, calls for help were mostly discussed followed by volunteering and coordination. It led to a great sense of cooperation in the network cluster, and this aided public and community response (Belblidia, 2010; Hjorth \& Kim, 2011; Starbird et al., 2010). Excluding that, the graph shows that it followed suit by showing that there was sketchy information and high clustering that depicted that the broadcasted network was bounded. The deviation amongst the stages was stable apart from the early stage which was a result of the 25 th data. The slight deviation which increased depicted that the growth in participation and slight differences between the periods themselves.

The need for information was reflected in the changes that occured in the network as there was a slight movement from information urgency to information saturation which peaked at the end of the flood date used in this study (4th January) with a total of 24 posts. It affected the network as the vital information was mostly from the onsite source which led to the broadcast pattern which was in stark contrast. There was an information overload in the network with the information being available from virtually everybody that formed the community pattern.

The state of the flood also came into play due to information needs, the number of participants and the information disseminators. From Table 2, it is evident that there was an increase in the metrics of evaluation except for graph density which was expected to drop because there were fewer interconnections and more intra-connections which led to a rise in the modularity, and equally more participants with less urgency. Table 3 follows the same pattern and shows the stabilization of the middle and the late periods which was different from the early stage of the flood.

\section{Graph Density}

Based on Table 3, it can be observed that the graph density of the network structures generated was different. The ICFP had a relatively dense network structure graph with an average graph density of 0.126631969 during the flood period. Meanwhile, the NGOFP had a graph density of 0.004. It was a very sparse graph even with the relatively low activity and participants on the page. The information about the urgent need for help during the flood and the need for information update after the flood play key roles in determining graph density and participation on the fan pages. It was dictated by some posts that were seen on each page and the generated clusters. As noted earlier, the ICFP had a denser graph than the NGOFP, which ought to be denser due to 
its relatively lower number of posts and participants. It showed the extent to which each page was active and the interconnection that existed between the participants.

More clusters existed in the ICFP, which was an indication of diverse people discussing the issue with varying opinions, with more clusters formed as days passed by and they were still connected. This finding is contrary to those found in NGOFP, in which the clusters were only connected during the flood and got sparse after the flood. Although on both pages, the density waned as time passed, the ICFP still had impressive activities going on the page, and this promoted a sense of community amongst the members and promoted bonding with each other. The bonding was highest in the community cluster; this is indicated by the high modularity that occured in the late flood phase. There was more bonding at the end of the flood period because of the sense of belonging to a community and the available information made deliberation and aggregation easier.

\section{Information Disseminators}

Both fan pages have very low percentages of influencers (information disseminators and information brokers) with an average of 5\%. The influencers are measured by their betweenness centrality if it is greater than 1 . Previous research has identified influencers based on their betweenness centrality (Abbasi \& Altmann, 2011; Michalski, 2015; Mohammadi, Saraee, \& Mirzaei, 2015). As shown in Figures 1 and 2, the importance of the node is identified by their color with blue representing the most influential and the dark yellow as the least influential.

In the ICFP, the influencers increased as time went by from $2.3 \%$ at the earliest part of the flood to a peak of $8.8 \%$ at the end of the flood. However, the rise was not consecutive or consistent; influencers increased as the flood period decreased. The active users on the ICFP were very high with an average of $98.2 \%$ active users compared to the $45 \%$ active users found on NGOFP. The active users were measured based on the strength of their social tie which was a summation of the users in and out degrees.

The influencers increased in the later weeks due to the availability of information. Overall, the percentage of influencers in both networks was very low at $5 \%$. It showed a major defect in the overall information coordination and dissemination and the need for better coverage (Guille, 2013; Mirbabaie, Ehnis, Stieglitz, \& Bunker, 2014). Although in the ICFP, the influencers increased as days passed from $2.3 \%$ on the first day to a peak of $8.8 \%$ on the last day. It 
depicted a wide gap between the informers and the information consumers. If this gap was not well managed, this could enable unethical informers or rumor peddlers to share unauthentic information and get broadcasted to the network (Uddin \& Amin, 2012). There should be more active participation from people with certified information and authority similar to the information influencers on social media during a disaster (Matar et al., 2016; Potter, 2016).

\section{Post and Cluster Analysis}

With each post expected to generate its audience and in turn have distinct clusters, the formation of the cluster in this regard is not according to the post but on the interconnectivity that exists between the participants. In the case of the NGOFP, most dense clusters are generated during the flood period as a result of people disseminating critical information. After the flood, there are more clusters, but they are very sparse in connectivity. While in the case of ICFP, on the average, the clusters are denser and active. They show the existence of more communication that exists among participants and linkage among the posts that gives room for continuous discussions.

\section{Post and Content Analysis}

At this stage, the posts were classified into themes. In general, ICFP had 157 posts while NGOFP had 139 posts. Both fan pages had five themes in common

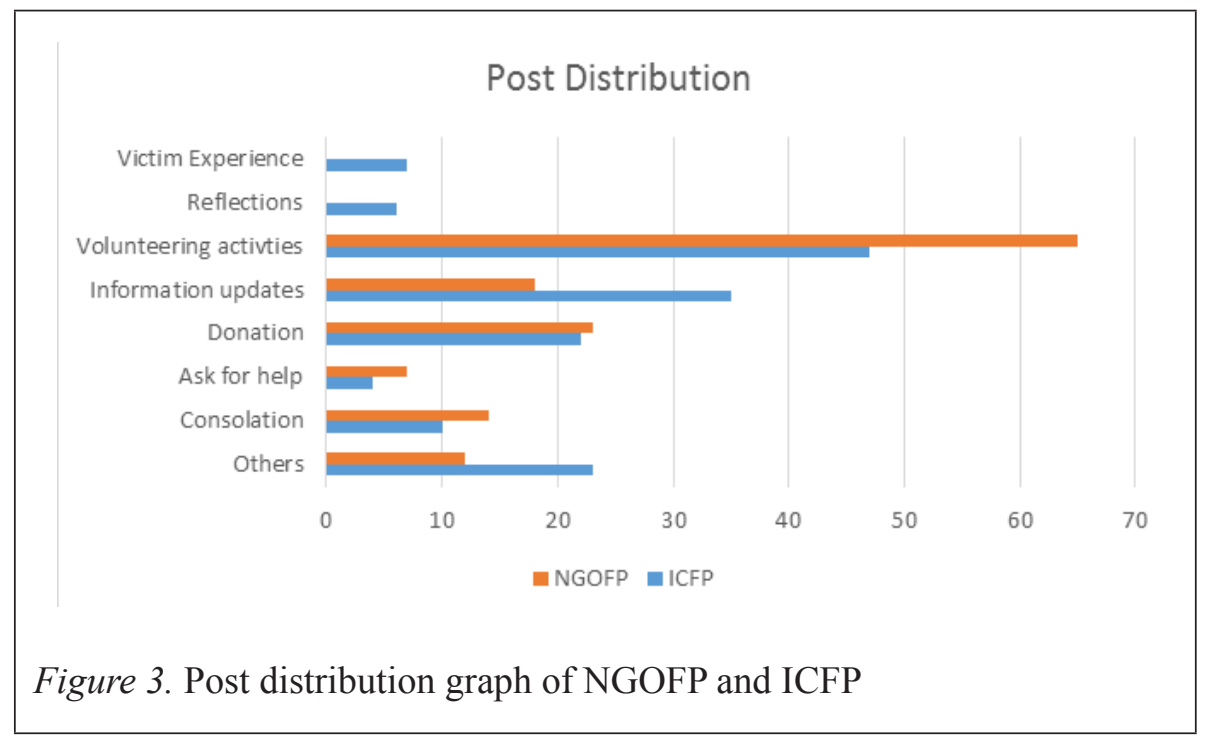


which were volunteering activities, information update, donation, asking for help and consolation. Meanwhile, ICFP had two extra themes which were the victims' experience and the page owner's reflections.

Category 1: Volunteering activities which are present during the flood and outnumber other themes. An example of a post in this section is:

"This morning, a friendly Volunteer Team went to Hospital Raja Perempuan Zainab II in Kota Bharu."

Category 2: The information update posts are utilized to deliver relevant news across, it includes the provision of a service portal for important details, and messages from high ranking people. An example of a post in this section is: all is well."

"There is a rumored water rise in some places. We pray that hopefully,

Category 3: In the donation and contribution post, the list of required items are issued, and details on how to contribute or move donated materials to the respective places are equally highlighted and thus help in relief operations for the flood victims. An example includes:

"There is still a need for basic equipment such as the water jet, etc. to help in the work of washing affected areas after the flood."

Category 4: The asking for help is more pronounced during the flood period where information about stranded people is posted. This is necessary for rescue coordination and awareness. They are the most commented posts on the fan page. An example includes:

"The people at the Bunut Payung National School are still requesting for help. Until now they have not received any assistance."

Category 5: The consolation theme is most pronounced in the third week and surfaces sparingly in other weeks. This is used to offer emotional support to the victims. An example includes:

"Prayer is needed for those affected by the test of faith. May all flood victims continue to persevere and be rewarded with benefit in the afterlife."

Category 6: The reflection category is primarily about Raja Shamri discussing his thoughts about the flood, and lessons learnt and mistakes made. It is seen towards the end of the data collection period. 
"This disaster has united us physically and virtually. This disaster forced us to place our focus on a central issue which is helping the flood victims."

Category 7: The victim experience category constitutes of posts where the victims share their ordeals during the flood.

"One doc shared her experience... She is working in hosp. Let's pray for these flood victims. If the water does not subside, maybe the patients will be evacuated using a helicopter because the oxygen supplies cannot last long. The electricity in the city has been cut-off. We are using a generator at the hospital which probably lasts $24-48$ hours."

The information exchanges that occurred in both pages were similar except that the ICFP included the victims' experiences and his personal reflections. The NGOFP gave more support and emotional assistance to the victims during the earlier phase of the flood using avenues like Islamic condolence messages and heartfelt messages to the victims. It related to the mixed feelings felt by those involved and the Islamic orientation that the page radiated, and this served as an emotional support for the affected victims (Carley et al., 2016; Yandong, 2010).

The case was different in the case of ICFP, which was an individual page and was much involved in information dissemination. Volunteering started earlier in the ICFP compared to the NGOFP due to the autonomous status of the civilians in organizing volunteers and raising donations. Furthermore, the citizens trusted the ICFP in disseminating information based on the belief that it was not a regimented page and the admin of the page was on site. It was proven by a recent study on the same flood (Tengku et al., 2015).

Donations of materials were visible on both pages and were regarded as crucial for relief coordination. This was seen in previous Malaysia floods (Chong et al., 2014). It was important to get the materials to the victims on the time when it was needed, and that reduced the amount of wastage that usually accompanied relief donations. During the flood, the information updates on both pages were crucial, but they declined with time. It could be related to the reduction of the severity of the flood, and thus the crucial need for information updates naturally decreased. The pressing need for keeping rescue teams upto-date during the flood period was decisive and genuine. Both pages helped in disseminating the location of stranded victims and thus helped in locating victims easily and quickly which could make a difference between survival and death. The request for help was similar each day during the flood period as the call for rescue always surfaced, and this was an overall imperative. 


\section{Gender Activity}

According to the Malaysian population projection for the year 2015, the current population range of males and females is almost equal (Department of Statistics, 2014). This does not reflect the proportion of activism amongst both genders on the online forums. Females were much more active on both ICFP and NGOFP. The gap's width was lesser in the NGOFP (females $25.1 \%$, males $22 \%$ ) compared to ICFP with an average of $67 \%$ females to $31 \%$ males. It may be attributed to the female's nature of compassion and empathy towards the flood victims. While this was a mere hypothesis and this area was beyond the scope of this study, some questions that needed to be raised would be recommended for further research. It would be imperative to establish if there

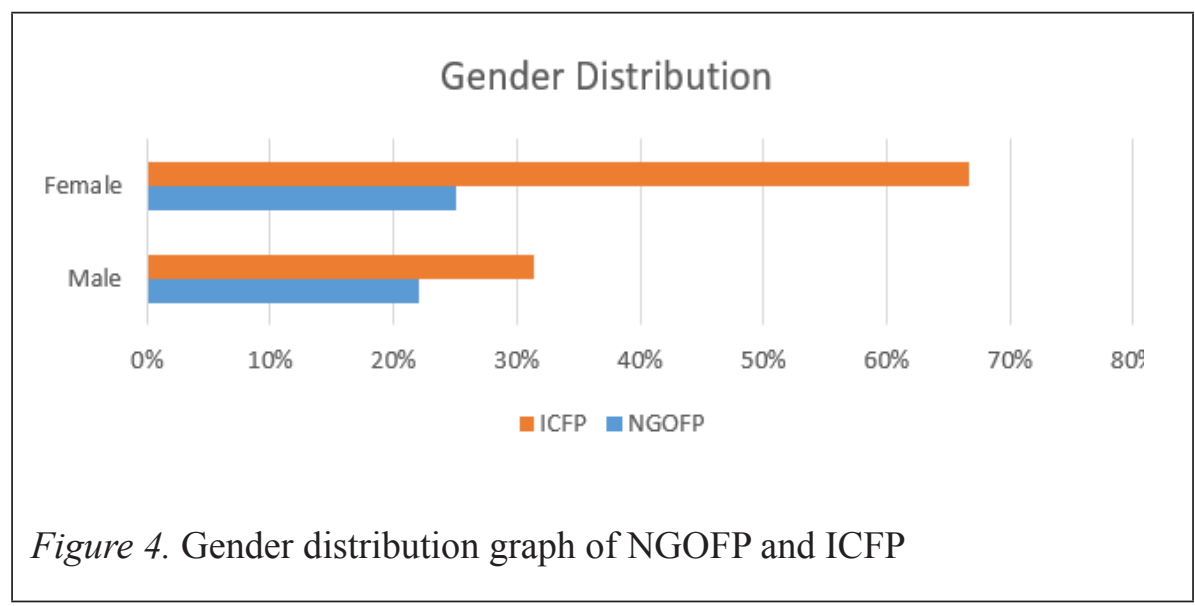

was higher IT literacy amongst the female population compared to the male, or the females were frequent users of social networks compared to their male counterparts that led to this vast gap in online activism. The next section elaborates the practical and theoretical implications of the study.

\section{IMPLICATIONS}

The implications of this study are two folds: practical and theoretical. The practical implication includes how social media assists in prioritizing the supply of aids based on the responses gathered. It can be implemented using a decision support system from the data collected from the social media. Equally, more research needs to be done on aggregating social media data for prioritizing areas which are severely impacted. It would aid in a more reliable rescue and relief coordination which would be more effective than 
a single user data. More research is needed for further improvement on how information disseminators and brokers could be enhanced which would enable information to reach the target audience in the shortest possible cycle.

The theoretical implications include a further study that highlights the crucial role social media plays on information dissemination in aiding victims of trauma and getting them more easily acquainted with the new environment. Equally, the comments have to be examined as the likes in the post, the effect of this on the overall network structure would be worth studying. Apart from that, there is a need to study sentiment analysis on real-time data to detect and predict people's reactions and needs, so effective relief and rescue operations can be launched. There is a need to evaluate gender activism and its effects on the social media and its impact in shaping information dissemination and how it is felt on social media.

\section{RECOMMENDATIONS}

This study arrived at several recommendations. First, there is a need to establish a synchronized relationship between participating bodies during a disaster. The government and other parastatals should have an avenue to handle large unstructured data to make it helpful during disaster periods. It would assist in effective coordination amongst them and enhance NGO activities for aiding and distributing relief materials. In the study of Nasaruddin et al. (2016) risk information from disaster provinces was used to display maps regarding the hazard location, its vulnerability, capacity and potential risk. Information synchronization from the participating bodies can not only perform the function of DRMIS (Nasaruddin et al., 2016) but also equally enhance it with regard to first-aid respondents and relief coordination. This relationship can be further strengthened through harmonization and unification of information disseminated based on social media.

Second, the enhancement of information dissemination amongst the influencers and target audience is needed. There should be more active participation, especially from authorized information providers, to increase the number of information brokers and to enable information to reach the target audience in the shortest cycle. The enhancement of active participation is achievable by devising ways in reducing the time taken to propagate information. One of the means to lessen the duration of information propagation is by delegating the responsibility of being an information source. Delegate it to the on-site people regardless of their influential status. Such a method would reduce the average time the crucial information needs to be distributed through to those 
who need the information and not the general populace which was the case in this research.

Third, based on the information brokers, there is the need to put a mechanism in place so that information posted is reliably verified. This would aid in the reduction of misinformation. As depicted from the content analysis, cases of rumors and false alarms can lead to the loss of lives and properties especially in scenarios where the legitimacy of a message is always in a spatio-temporal context. Verification is required to reduce the rate of misinformation, and it can be implemented using upvotes or downvotes found in the Digg social network. This community crowdsourcing of information and information urgency would verify the information sources and enhance the rate of the information spread. Equally, an official online forum should be put in place. This forum can accommodate urgent requests for information or dissemination which aids in the rescue operations.

Finally, the social media should be continually used for fostering and enhancing emotional assistance and support for affected victims to reduce post-disaster trauma. Since the social media has been proven to enhance community resilience and also offer emotional support to disaster victims, its utilization should be maximized through frequent posts and updates as seen in the NGOFP.

\section{CONCLUSION}

In answering the first research question, it is apparent that in identifying the key players during the flood, on average only $5 \%$ of the population are instrumental in sourcing and bridging information. In the context of this study, the key influencers were civilians with extremely few organizations and no participation from the media. It is partly due to the reason that this research was conducted from a civilian's, and an organization's points of view, hence the key players and information exchanged are expected to vary from that of the media houses.

The second research question was answered by showing that different information exchanges took place during the flood which can be divided into eight broad categories. All the information exchanged in the categories was crucial and needed at various points of time during the flood. These typical information exchanges give rise to the mode of participation in online activities. 
The answer to the third research question showed that the social network structure generated during the flood changes depended on various conditions such as the current state of the flood, amount of information available and the nature of the information needed. The conditions formed the central building block for the network structure transition from the broadcast pattern to the tight crowd pattern and the community cluster pattern as visualized in the network structure.

\section{REFERENCES}

Abbasi, A., \& Altmann, J. (2011). On the correlation between research performance and social network analysis measures applied to research collaboration networks. 2011 44th Hawaii International Conference on System Sciences, 1-10. http://doi.org/10.1109/HICSS.2011.325

Akhtar, N., Javed, H., \& Sengar, G. (2013). Analysis of Facebook Social Network. 2013 5th International Conference on Computational Intelligence and Communication Networks, 451-454. http://doi. org/10.1109/CICN.2013.99

Alidmat, O. K. A., Khader, T., \& Hassan, F. H. (2016). Two-dimensional cellular automaton model to simulate pedestrian evacuation under fire-spreading conditions. Journal of Information \& Communication Technology, 15(1), 83-105.

Anzai, S., \& Matsuzawa, C. (2013). Missions of the Japanese National University Corporations in the 21st Century: Content analysis of mission statements. Academic Journal of Interdisciplinary Studies, 2(3), 197. http://doi.org/10.5901/ajis.2013.v2n3p197

Belblidia, M. S. (2010). Building community resilience through social networking sites. International Journal of Information Systems for Crisis Response and Management, 2(March), 24-36. http://doi. org/10.4018/jiscrm.2010120403

Bunce, S., Partridge, H., \& Davis, K. (2011). Exploring information experience using social media during the 2011 Queensland floods : A pilot study . The Australian Library Journal, 61, 34-45. http://doi.org/10.1080/000 49670.2012.10722300

Carley, K. M., Malik, M., Landwehr, P. M., Pfeffer, J., \& Kowalchuck, M. (2016). Crowd sourcing disaster management: The complex nature 
of Twitter usage in Padang Indonesia. Safety Science. http://doi. org/10.1016/j.ssci.2016.04.002

Chen, L. J., Li, C. W., Huang, Y. Te, \& Shih, C. S. (2011). A rapid method for detecting geographically disconnected areas after disasters. IEEE International Conference on Technologies for Homeland Security (HST'11), 501-506. http://doi.org/10.1109/THS.2011.6107919

Chong, T., Leong, C., Pan, S., Bahri, S., \& Fauzi, A. (2014). Use of social media in disaster relief during the Kuantan (Malaysia) flood. International Conference on Information Systems, 1-9. Retrieved from http://aisel. aisnet.org/icis2014/proceedings/ISCurriculum/3

Cote, E., \& Hearn, R. (2016). The medical response to the Boston Marathon bombings: An analysis of social media commentary and professional opinion. Perspectives in Public Health, XX(X), 1-6. http://doi. org/10.1177/1757913916644480

Denef, S., Augustin, S., Bayerl, P. S., \& Kaptein, N. (2013). Social Media and the Police - tweeting practices of British police forces during the August 2011 riots. Chi 2013, (August 2011), 1-10. http://doi. org/10.1145/2470654.2466477

Department of Statistics, M. (2014). ICT use and access by individuals and households survey 2013.

Guille, A. (2013). Information diffusion in online social networks. Proceedings of the 2013 Sigmod/PODS Ph.D. Symposium on PhD Symposium, 3136. http://doi.org/10.1145/2483574.2483575

Hansen, D. L., Rotman, D., Bonsignore, E., Milic-Frayling, N., Rodrigues, E. M., Smith, M., \& Shneiderman, B. (2013). Do you know the way to SNA': A process model for analyzing and visualizing social media network data. Proceedings of the 2012 ASE International Conference on Social Informatics, Social Informatics 2012, 304-313. http://doi. org/10.1109/SocialInformatics.2012.26

Hansen, D. L., Shneiderman, B., \& Smith, M. A. (2011). Analyzing social media networks with NodeXL: Insights from a connected world. Analyzing Social Media Networks with NodeXL. Elsevier Inc. http:// doi.org/10.1016/B978-0-12-382229-1.00002-3 
Higuchi, K. (2001). Kh coder. Retrieved from http://khc.sourceforge.net/en/

Himelboim, I., Mccreery, S., \& Smith, M. (2013). Birds of a feather tweet together: Integrating network and content analyses to examine cross-Ideology exposure on twitter. Journal of Computer-Mediated Communication, 18, 40-60. http://doi.org/10.1111/jcc4.12001

Hjorth, L., \& Kim, K. -h. Y. (2011). The mourning after: A case study of social media in the 3.11 earthquake disaster in Japan. Television \& New Media, 12, 552-559. http://doi.org/10.1177/1527476411418351

Hughes, A. L. (2014). Participatory design for the social media needs of emergency public information officers. 11th International ISCRAM Conference, (May), 722-731.

Hughes, A. L., \& Palen, L. (2012). The evolving role of the public information officer: An examination of social media in emergency management. Journal of Homeland Security and Emergency Management, 9. Retrieved from $<$ Go to ISI $>$ ://WOS:000305695600011

Hughes, A. L., St. Denis, L. A., Palen, L., \& Anderson, K. M. (2014). Online public communications by police \& fire services during the 2012 Hurricane Sandy. Proceedings of the 32nd Annual ACM Conference on Human Factors in Computing Systems - CHI '14, 1505-1514. http:// doi.org/10.1145/2556288.2557227

Kaplan, A. M., \& Haenlein, M. (2010). Users of the world, unite! The challenges and opportunities of social media. Business Horizons, 53, 59-68. http://doi.org/10.1016/j.bushor.2009.09.003

Kelly, A. R., \& Autry, M. K. (2011). A humanistic approach to the study of social media : \& case study research. In SIGDOC'11 (pp. 257-260). http://doi.org/10.1145/2038476.2038525

Lai, L., \& Turban, E. (2008). Groups formation and operations in the Web 2.0 environment and social networks. Group Decision and Negotiation, 17, $387-402$.

Lu, H.-Y., Case, D. O., Lustria, M. L. A., Kwon, N., Andrews, J. E., Cavendish, S. E., \& Floyd, B. R. (2007). Predictors of online information seeking by international students when disaster strikes their countries. Cyberpsychology \& Behavior : The Impact of the Internet, Multimedia 
and Virtual Reality on Behavior and Society, 10, 709-712. http://doi. org/10.1089/cpb.2007.9965

Matar, S., Matar, N., Balachandran, W., \& Hunaiti, Z. (2016). Social media platforms and its applications in natural disaster and crisis events - the case of Bosnia \& Herzegovina. IISTE, 6(5), 50-56.

Matuszka, T., Vinceller, Z., \& Laki, S. (2013). On a keyword-life cycle model for real-time event detection in social network data. In 2013 IEEE 4th International Conference on Cognitive Infocommunications (CogInfoCom) (pp. 453-458). http://doi.org/10.1109/ CogInfoCom.2013.6719289

Mendoza, M., Poblete, B., \& Castillo, C. (2010). Twitter Under Crisis: Can we trust what we RT? Workshop on Social Media Analytics, 9. Retrieved from http://doi.org/10.1145/1964858.1964869

Michalski, R. (2015). Linear threshold model in temporal networks - Seed selection for social influence. In Proceedings of the 2015 IEEE/ACM International Conference on Advances in Social Networks Analysis and Mining 2015 (pp. 922-923). ACM.

Mirbabaie, M., Ehnis, C., Stieglitz, S., \& Bunker, D. (2014). Communication roles in public events - A case study on twitter communication. In Information Systems and Global Assemblages. (Re)Configuring Actors, Artefacts, Organizations (pp. 207-218).

Mohammadi, A., Saraee, M., \& Mirzaei, A. (2015). Time-sensitive influence maximization in social networks. Journal of Information Science, 41(6), 765-778. http://doi.org/10.1177/1045389X14554132

Nagar, S., Seth,A., \& Joshi,A. (2012). Characterization of social media response to natural disasters, 671-674. http://doi.org/10.1145/2187980.2188177

Nasaruddin, Ardiansyah, \& Khairul, M. (2016). Interactive Internet-based disaster risk information system for tsunami-hit Aceh province of Indonesia. Journal of Information \& Communication Technology, 15(1), 33-55.

Nur, W., Wan, T., Nor, H., Zakaria, H., \& Nazir, M. (2015). Knowledge sharing and lesson learned from flood disaster : A case in Kelantan, 9 (August), $1-10$. 
Palen, L., Hiltz, S. R., \& Liu, S. B. (2007). Online forums supporting grassroot participation in emergency preparedness and response. Communications of the ACM. http://doi.org/10.1145/1226736.1226766

Pew Research Center. (2013). How we analyzed twitter social media networks with NodeXL.

Potter, E. (2016). Balancing conflicting operational and communications priorities : Social media use in an emergency management organization. In Long Paper - Social Media Studies Proceedings of the ISCRAM 2016 Conference. Rio de Janeiro, Brazil.

Preece, G., Shaw, D., \& Hayashi, H. (2014). Application of the viable system model to analyse communications structures : A case study of disaster response in Japan. European Journal of Operational Research, 243(1), 312-322. http://doi.org/10.1016/j.ejor.2014.11.026

Qu, Y., Wu, P., \& Wang, X. (2009). Online community response to major disaster: A case study of Tianya Forum in the 2008 China earthquake, (January). http://doi.org/10.1109/HICSS.2009.330

Reuters. (2014). Record numbers evacuated in Malaysia's worst floods in decades. Retrieved February 14, 2015, from http://www.investing.com/ news/world-news/record-numbers-evacuated-in-malaysia\% 27 s-worstfloods-in-decades-321473

Samsudin, N., Puteh, M., Hamdan, A. R., \& Nazri, M. Z. A. (2013). Normalization of noisy texts in Malaysian online reviews. Journal of Information \& Communication Technology, 12, 147-159.

Scholand, A. J., Tausczik, Y. R., \& Pennebaker, J. W. (2010). Social language network analysis. Proceedings of the 2010 ACM Conference on Computer Supported Cooperative Work - CSCW '10, 23. http://doi. org/10.1145/1718918.1718925

Smith, M. A. (2013). NodeXL: Simple network analysis for social media. 2013 International Conference on Collaboration Technologies and Systems (CTS), 89-93. http://doi.org/10.1109/CTS.2013.6567211

Smith, M. A. (2014). Identifying and shifting social media network patterns with NodeXL. 2014 International Conference on Collaboration Technologies and Systems (CTS), 3-8. http://doi.org/10.1109/ CTS.2014.6867534 
Song, M., Kim, M. C., \& Jeong, Y. K. (2014). Analyzing the political landscape of 2012 Korean presidential election in twitter. IEEE Intelligent Systems, 29(2), 18-26. http://doi.org/10.1109/MIS.2014.20

St. Denis, L. A., Hughes, A. L., \& Palen, L. (2012). Trial by fire: The deployment of trusted digital volunteers in the 2011 Shadow Lake fire. Iscram, (April), 1-10.

Starbird, K., Palen, L., Hughes, A. L., \& Vieweg, S. (2010). Chatter on the red: What hazards thret reveals about the social life of microblogges information. Proceedings of the Conference on Computer Supported Cooperative Work (CSCW), 241-250.

Sutton, J., Palen, L., \& Shklovski, I. (2008). Backchannels on the front lines : Emergent uses of social media in the 2007 Southern California wildfires, (May).

Tang, T., Hämäläinen, M., Virolainen, A., \& Makkonen, J. (2011). Understanding user behavior in a local social media platform by social network analysis. Proceedings of the 15th International Academic MindTrek Conference on Envisioning Future Media Environments MindTrek'11, 183. http://doi.org/10.1145/2181037.2181067

Tengku, S. A., Wok, S., Manaf, A. M. A., \& Ismail, R. (2015). Exploring the use of social media during the 2014 Flood in Malaysia. Procedia Social and Behavioral Sciences, 211(September), 931-937. http://doi. org/10.1016/j.sbspro.2015.11.123

Thakur, N. (2012). A concept development methodology: Disaster relief. IEEE Conference on Technology and Society in ASIS (T\&SA). Doi: 10.1109/TSAsia.2012.6397974.

Uddin, M., \& Amin, M. (2012). On diversifying source selection in social sensing. Networked Sensing Systems (INSS), 1-8. Retrieved from http:// ieeexplore.ieee.org/xpls/abs_all.jsp?arnumber $=6240519$

Vieweg, S., Hughes, A. L., Starbird, K., \& Palen, L. (2010). Microblogging during two natural hazards events. Proceedings of the 28th International Conference on Human Factors in Computing Systems - CHI '10, 1079. http://doi.org/10.1145/1753326.1753486

Wakita, K., \& Tsurumi, T. (2007). Finding community structure in mega-scale social networks. In The 16th International Conference on World Wide Web (pp. 1275-1276). ACM. 
Wikipedia. (2015). 2014-15 Malaysia floods. Retrieved February 14, 2015, from http://en.wikipedia.org/wiki/2014\%E2\%80\%9315_Malaysia_floods

Yandong, Z. (2010). Social networks and reduction of risk in disasters : An example of Wenchuan earthquake. International Conference on Economic Stress, Human Capital and Families in Asia, 1-13.

Yates, D., \& Paquette, S. (2011). A case study of the 2010 Haitian earthquake. International Journal of Information Management, 31(1), 6-13. 